\title{
Advertising break in sustainability of education
}

\author{
Tatyana Filippovskaya ${ }^{1, *}$, Inna Klimenteva ${ }^{2}$, and Svetlana Diakonova ${ }^{1}$ \\ ${ }^{1}$ Ural State University of Economics, 8 March Str., 62, 620144 Yekaterinburg, Russia \\ ${ }^{2}$ Russian State Vocational Pedagogical University, Mashinostroiteley Str., 11, 620012 Yekaterinburg, \\ Russia
}

\begin{abstract}
The aim set by the authors of the present article is to consider the psychological, pedagogical, legal and economic contexts of the negative impact of advertising in the media (mass media) on the creative potential of population. The novelty of the undertaken research lies in an attempt to comprehensively assess the cause-and-effect relationships of one of the sides of the process of developing students' fragmented thinking, which reduces stability of the educational system and, consequently, the stability of the entire society. Materials and methods include a review of analytical assessments presented in the Scopus, Web of Science, CyberLeninka, RSCI and others databases, as well as application of the methodology of analysis, synthesis, generalization of the results of qualitative author's and secondary research. As a result of the study, systemic violations of the legislation on the protection of children from information harmful to their mental health were revealed. The economic effect of the systematic appeal of the media to advertising contexts was shown, which arises contrary to the laws of the economy, when the service to the consumer (viewer, reader, user of IT technologies) is not requested, but forcibly provided, while the cancellation of it is realizable only with additional payment for ad blocking by third parties. The article also reveals the negative effect manifested in the political stability of society, resulting from the long-term destructive influence of advertising on the viewer's thinking through the formation of fragmentary thinking of citizens, minimizing the level of their readiness to establish cause-and-effect relationships in assessing individual activity and events in society. In conclusion proposals are given for eliminating violations of the law and increasing the stability of society on the basis of increasing the stability of the education system to the negative impact of external education.
\end{abstract}

\section{Introduction}

The problems of the negative impact of sources of education external to educational organizations that affect the behavioral practices of citizens are rarely described at the level of an interdisciplinary approach. One such source of "anti-education" is advertising. The traditional "gimmick" of referring to advertising as the "engine of commerce" lacks the strong economic evidence that many authors try to predict. This position is understandable:

\footnotetext{
* Corresponding author: ftatyana@mail.ru
} 
too many entities receive a real economic effect from the practically uncontrolled process of forced provision of services that are not requested by the consumer (viewer, reader, user of IT technologies) from the media. At the same time, the educational system, on the stability of which the stability of society inevitably depends, exists in the face of struggle with fragmented thinking, dystrophy of the skills of establishing cause-and-effect relationships of subjects who receive systemic "antidevelopment" in conditions of mass education outside educational institutions. The authors' attempt to consider the economic, legal and psychological-pedagogical context of the national advertising dictatorship in connection with the provisions mentioned above is relevant.

\section{Materials and Methods}

A review of analytical assessment presented in the Scopus, Web of Science, CyberLeninka, RSCI and other databases have been used to apply the methodology of analysis, synthesis, and generalization of the results gained by the authors and secondary qualitative research.

The study was carried out taking into account the Federal Law of December 29, 2010 No. 436-FL "On the Protection of Children from Information Harmful to Their Health and Development" (hereinafter - 436-FL), the latest version of the Federal Law "On Advertising" dated 03.13.2006 N 38-FL (hereinafter - 38-FL), Federal Law of January 13, $1995 \mathrm{~N} 7-\mathrm{FL}$ "On the procedure for covering the activities of state authorities in the state media" (hereinafter - 7-FL) and other regulatory legal acts.

The sociological context of the undertaken research was based on an express survey of 176 full-time students of the Ural State University of Economics, conducted in 2018-2019, 12 teachers of higher education, 5 teachers of secondary schools with more than 15 years of teaching experience. The aim of the survey was to verify the data of secondary studies of attitudes towards advertising conducted by national research structures. The results of the survey of students and teachers coincided with the actual results of professional sociologists. At the same time, the obtained qualitative assessments partially became illustrations of the provisions stated by the authors and are highlighted in italics.

\section{Results and Discussion}

L.T. Benjamin and D.B. Baker remind that the dictatorship of advertising began to be established with the practical implementation of the conclusions made by Walter Dill Scott in "The Theory and Practice of Advertising" which has become a classic today [1, p. 120]. The quotation of Walter Dill Scott given by the researchers indicates that a person, although called an intelligent animal, is better considered "the creature of suggestion", since his mind is largely amenable to suggestion.

Modern Russian scientists are actively developing foreign concepts of the early XXth century. Thus, K.V. Popova successfully describes strategies of prevention, argumentation and persuasion based on the nuances of linguistics [2]. I. D. Romanova and I. V. Smirnova consider methods of persuasion as features of rhetoric within the logo ("logical reasoning"), ethos ("company image") and pathos (emotional component ") [3]. E. A. Danilina, E. E. Kizyan, D. S. Maksimova summarize the experience of euphemization, positioned as a linguistic tool and a manipulation mechanism, "tuned" so as to "comply with generally accepted standards of speech etiquette" [4]. G. Mikhaleva presents the options for using the analysis of media advertising messages in the process of teaching students and points out that today it is difficult to find something completely new in the variety of "advertising techniques and tricks in the media" [5]. 
Indeed, uniformity is increasingly embracing the field of commercials, for example, on television. Advertising of medicines is repeated almost every 14-15 minutes with a presentation of the anatomical details of the effect of chemistry on the human body.

"Aging and graying actresses, who are apparently a rare appearance on the stage, unexpectedly discover two-month gray hair and grab the hair dye with horror. It seems rather strange: our women, unlike actresses from abroad, monthly turn to a hairdresser or to the same paint due to the habit of systematically taking care of themselves".

"The number of commercials in which foreign performers are involved has dramatically increased. The Russian dubbing simply does not coincide with their articulation, and it is even funnier when dark-skinned actors offer us advertising for soap in Russia. It's simply annoying when they show us strange groups of dancers with a foreign idea of how many people of different nationalities and genders should be presented. Just take a look at their movements and all this twitching of lower parts of their bodies when advertising jeans ... Every dance movement should make sense, but here it is absolutely devoid of aesthetics and traditions - what they only run is foreign advertisements".

"And here is an example of our actors with an advertisement for home delivery of groceries: there is nothing worse than a lady, a former peasant woman. Just listen to her tortured and smug: "Put it here, dear".

The presented above reasoning of the respondents testifies of the fact that there is a clear mismatch between the norms of the Russian language, adopted even in dubbing, national dance movements and attitudes towards them, patterns of behavior and what we actually see on TV.

"Every 15-17 minutes films and interesting programs are interrupted for 7-10 minutes. There is a presentation of promising screenings of films and programs, after which neither films nor programs are interesting to watch: endless repetition irritates. Who needs this trick: information about promising shows is also an advertisement - but many people just don't watch TV anymore. The Internet is just awful, and games on smart-phones literally choke on ads".

Let us turn to the legislative grounds for such interference in the private practices of citizens of our country. First of all, attention should be paid to the fact that children, as the pandemic showed, are not always limited by their parents in watching programs, for example, on television. As a result, from early morning until late at night they are imposed on information that is practically prohibited by 436-FL. Such information includes any form, the material of which contains scenes of violence, cruelty, sexual deviations and relationships, illegal behavior. The list is wide enough and includes an appeal to the age range. However, the essence of this does not change: children with perseverance worthy of better use are imposed on models that are poorly compatible with national ideas about good and evil, permissible body movements, relationships and actions.

As one of the co-authors noted in their analysis of the current situation, "everything or practically everything that is shown in the daytime and in the evening on the "commonly used' central channels, including endless talk shows with shouts, yells and unwillingness to listen to the interlocutor, an attempt to introduce the public to the intimate life of fellow citizens in its various aspects - it turns out that it harms, first of all, the moral development (and psychological, of course) of children of all age groups" [6].

The consumption of news and advertising content is growing every year, however, the audience's trust in the media is declining. According to research by the consulting company Edelman, Russia is the state with the lowest level of trust in the media [7]. As evidence of this, in 2020 only $28 \%$ of Russians surveyed trust the media, which is $2 \%$ more than in 2019. More than half of the respondents $(57 \%)$ believe that the media they regularly read and watch consist of unverified and unreliable information. In 2020 the share of respondents who believe that the media and false news can be used "as a weapon" was 
$76 \%$, which is $6 \%$ higher than the data for $2018.72 \%$ of respondents believe that if the channel uses unverified and inaccurate information, then the advertiser should not cooperate with it.

Advertising has long become part and parcel of everyday life: $70 \%$ of Russians often see it on TV, $50 \%$ on the Internet. At the same time, it is perceived more as a hindrance than necessary information: when watching a program/film on TV $41 \%$ of respondents are distracted by their business at the time of a commercial break, 30\% switch the channel. Only $14 \%$ of respondents watch and listen to commercials (in $2012-9 \%$ ), another 4\% watch them in silent mode.

The level of trust in advertising in our society remains low: only 3\% of respondents trust advertising information, while $57 \%$ say the opposite, another $38 \%$ take an intermediate position ("I partly trust, partly I don't trust") [8]. An interesting fact is the direct dependence of the frequency of watching TV on age: the younger the respondents, the less often they watch TV. There is a dependence of the frequency of viewing advertisements on the Internet on age: the younger the respondents, the more often they watch advertisements on the Internet.

Thus, on the one hand, we see that the legal regulations for the presentation of information that does not violate the moral and mental development of children and adolescents are violated. On the other hand, the population, regardless of the source of advertising content, does not trust the information imposed. Hence is the question: why are the commercials and the lengthy descriptions of promising impressions attached to them increasingly taking the attention of viewers? Who should control this imbalance?

Rospotrebnadzor conducts state control over the reflection of information related to age classification in the accompanying documents of information products. The Ministry of Culture determines the procedure for placing the corresponding signs. Rosobrnadzor restricts the flow of inappropriate information to educational institutions and organizations. At the same time, the Ministry of Telecom and Mass Communications of the Russian Federation is responsible for the development and implementation of state policy in the media space. Roskomnadzor supervises the abuse of freedom of the media. According to the reported data from the official website of this structure, 42,850 citizens applied to Roskomnadzor in 2018 and 27,123 in 2019 with demands to take action on the administrators of sites where illegal information is disseminated. Such a decrease in figures may testify of either a decrease in confidence in the effectiveness of the controller's actions, or a redistribution of the content of appeals between this and other state structures that control the 'permissiveness of freedom'. Of the 154,274 citizens' appeals in 2019 only $3 \%$ concerned the media. In the first quarter of 2020, growth was outlined - 8, 64\% (501 questions about the content of materials published in the media, including in electronic media). There were complaints about violation of Federal Law 436 (pornography, drugs, suicide, propaganda of non-traditional sexual relations) amounting to 1,474 episodes in 2018, and to 1,794 in 2019.

However, the situation is only getting worse while advertising context providers are significantly increasing their profits. VGTRK is the largest state broadcaster. In 2018, the channel's revenue amounted to 32.4 billion rubles, expenses amounted to 57.2 billion rubles. The resulting loss of 24.8 billion rubles from the main activity is covered by "other sources of income" amounting to 27 billion rubles, which include subsidies from the budget. In 2019, VGTRK received almost 26 billion rubles from the budget [9]. According to the appendix to the bill "On the federal budget for 2020 and for the planning period 2021 and 2022" VGTRK, Channel One, NTV and RT in three years will receive subsidies from the budget in the amount of more than 148 billion rubles. According to the Association of Communication Agencies of Russia (ACAR), published on the official website of the organization, advertising is an additional and powerful source of funding - the total volume 
of advertising in its distribution media, net of VAT, amounted to almost 493.8 billion rubles, which is 5\% more than in 2018. In 2019, advertising on the Internet brought in revenue of 244 billion rubles, and on television - 175 billion rubles.

As one can see, advertising is a very profitable segment of economic activity. Hardly anyone will deny it. At the same time, it is advertising and the ways of its presentation that directly influence the growth of the phenomenon called fragmentary/clip thinking in educational psychology. O. A. Staritsyna states: "Scientists characterize the thinking of modern youth as clip-like, which is basically superficial, fragmentary, has illogicality, a violation of cause-and-effect relationships" [10]. At the same time, we disagree with the author that the traditional system of education does not correspond to innovations in the worldview and the ability to work with information of modern youth. The main tradition is to be able to find such options for working with trainees that are most consistent with their psychological capabilities. But the education system accepts the contingent that has already been formed by the education system operating outside of schools and universities. The presentation of information in the media - on television and on the Internet - plays a huge role here. As a result, dominant is "the orientation towards a rational-pragmatic approach to the value of knowledge (which orients an action based on artifacts - symbols, traditions, rituals), to ideals and goals of the community, to benefits over the costs of interaction resources. The functions of the value of knowledge are the acceptance of procedural knowledge and the denial of "unnecessary" knowledge, increasing the importance of procedural knowledge and reducing the importance of declarative knowledge. In social intelligence, procedural knowledge plays a leading role. The contextual component of declarative knowledge dominates conceptual knowledge about the social world. The social network is closed on the participants of actual interactions and changes at every step of mobility [11]. The conclusion is drawn: "Where the mindset on the value of knowledge dominates without guarantees of community going beyond the framework of utilitarianism and pragmatic rationalism, the entire society is self-excluded from modernization processes." That is, the dystrophy of the skills of establishing cause-and-effect relationships of subjects receiving systemic "antidevelopment" in the conditions of mass education outside educational organizations threatens the stability of the education system and, ultimately, the society.

V. V. Kuzmin and Yu. S. Obidina emphasize the fact that advertising in particular and ideology of presenting materials on television in general is a source of fragmentary / clip thinking. The authors conclude that it is advertising that contributes to the decomposition of the "linear logical structure of society, forming a new kind of person with fragmented, emotional-figurative thinking - HomoFiguralis" [12].

\section{Conclusion}

The goal set by the authors during the preparation of the publication made it possible, at the level of an interdisciplinary approach, to present the psychological, pedagogical, legal and economic contexts of the negative influence of advertising in the media (mass media) on the creative potential of the population. The article presents an analysis of a significant array of publications on the specifics of assessments of modern researchers, concerning, as a rule, the essence of advertising, ways and methods of enhancing its impact on the audience. At the same time, the existing references to the description of the negative impact of media advertising policy on the cognitive development of young people, which requires the sustainability of the education system to solve the problems it faces (O. Kornuta, T. Pryhorovska, N. Potiomkina [13]), do not always demonstrate evidence to the expressed views. What is needed is an in-depth analysis of the influence of a large fan of facets that deform the consciousness and thinking of young people, which the educational system 
cannot radically correct, since many negative behavioral characteristics are laid down by the subjects of education external to educational organizations. For example, interesting are the conclusions of S. Shomova about the reflection of political Internet memes at the level of social stability [14].

At the same time, today there are significant niches in the legal field of advertising. Thus, according to 7-FL, it is prohibited to "insert" advertising into the presentation of government messages. According to $38-\mathrm{FL}$, broadcasting live, in the recording of sports matches, races, various games and fights, can be interrupted by advertising only during official breaks of the sports process. It should be pointed out that the same legislative act allows for the interruption of films that are classics of the national cinema for advertising messages. It seems that this is unacceptable, first of all, from the point of view of respect for the national values enshrined in the Constitution of the country, as well as at the level of participation of the education system by means of the media in the development of viewers' skills of consistent mastering of information, the ability to find cause-and-effect relationships in the behavior of heroes and comprehending events. Also, changes should be made to 436-FL. Today, it is advertising that does not fall within the sphere of influence of the legislative act on the protection of children from information that harms their moral and mental health and, ultimately, models of interiorized socially approved behavioral strategies. In this regard, fundamental changes regarding the time of inclusion of commercials in the broadcasting network should be made to the federal law 38-FL. Their place is only between completed films and programs. Moreover, stories with advertising of medical products, as well as with a demonstration of anatomical features of the human body, should be demonstrated only on specialized sites and only with comments from specialists about the dangers of self-medication and self-diagnosis.

A website on which caring consumers had the opportunity to leave their suggestions, appeals regarding violations of moral, ethical, moral norms, traditionally present in the national practices of everyday life, could become a significant help in the work of the country's Roskomnadzor. A substantial effect could be expected from a survey of television viewers and citizens of the country about television channels that should be completely free from advertising and funded by the state. Particular attention should be paid to the violation of economic laws, when the consumer did not order advertising, but can refuse it only after paying for the corresponding services from third parties. Such a disproportion in violation of consumer rights to information in demand should also be eliminated.

\section{References}

1. L. T. Benjamin, D. B. Baker, Séance to Science: A History of the Profession of Psychology in America, 118 (2004)

2. K. V. Popova, Training, Language and Culture, 2(2), 55 (2018)

3. I. D. Romanova, I. V. Smirnova, Training, Language and Culture, 3(2), 55 (2019)

4. E.A. Danilina, E.E. Kizyan, D.S. Maksimova, Training, Language and Culture, 3(1), 8 (2019)

5. G. Mikhaleva, Classroom International Journal of Media and Information Literacy, 4(2), 41 (2019)

6. T.V. Filippovskaya, Legislative authorization depravation (2020), http://worldcrisis.ru/

7. Edelman Trust Barometer 2020, https://www.edelman.com/

8. VCIOM-SPUTNIK: Approval of the activities of public institutions. Analytical review, https://wciom.ru/

9. Consolidated budget of the Russian Federation, https://minfin.gov.ru/ 
10. O. A. Staritsyna, Azimuth of Scientific Research: Pedagogy and Psychology, 7, 2(23), 270 (2018)

11. T. V. Filippovskaya, Risks of reflexive modernization under conditions of aggravation of antagonism of knowledge and non-knowledge, 294 (2013)

12. V. V. Kuzmin, Yu. S., Juvenis Scientia, 7, 28 (2019)

13. O. Kornuta, T. Pryhorovska, N. Potiomkina, Open educational e-environment of modern university, 3, 75 (2017)

14. S. Shomova, Higher School of Economics Research Paper (2019), https://ssrn.com/ 